\title{
Oridonin inhibits gefitinib-resistant lung cancer cells by suppressing EGFR/ERK/MMP-12 and CIP2A/Akt signaling pathways
}

\author{
XIANGLING XIAO $^{1 *}$, ZHONGWEI HE $^{1 *}$, WEI CAO $^{2}$, FEN CAI $^{1}$, LIANG ZHANG $^{1}$, QIUYUE HUANG $^{1}$,

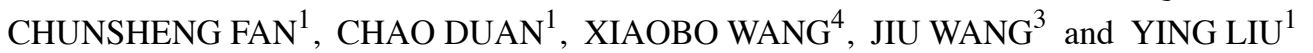 \\ ${ }^{1}$ School of Basic Medical Sciences, Hubei University of Medicine, Shiyan, Hubei $442000 ;{ }^{2}$ School of Life Sciences, Tsinghua \\ University, Beijing 100084; ${ }^{3}$ School of Pharmaceutical Sciences, Hubei University of Medicine, Shiyan, Hubei 442000; \\ ${ }^{4}$ Translational Medical Center, Suizhou Central Hospital, Hubei University of Medicine, Suizhou, Hubei 441300, P.R. China
}

Received February 16, 2016; Accepted March 24, 2016

DOI: $10.3892 /$ ijo.2016.3488

\begin{abstract}
Oridonin (Ori), a diterpenoid compound extracted from traditional medicinal herbs, elicits antitumor effects on many cancer types. However, whether Ori can be used in gefitinib-resistant non-small cell lung cancer (NSCLC) cells remains unclear. This study investigated the antitumor activity and underlying mechanisms of Ori. Results demonstrated that this compound dose-dependently inhibited the proliferation, invasion, and migration of the gefitinib-resistant NSCLC cells in vitro. Ori also significantly downregulated the phosphorylation of EGFR, ERK, Akt, expression levels of matrix metalloproteinase-12 (MMP-12), and the cancerous inhibitor of protein phosphatase 2A (CIP2A). In addition, Ori upregulated protein phosphatase 2A (PP2A) activity of gefitinib-resistant NSCLC cells. Ori combined with docetaxel synergistically inhibited these cells. Ori also inhibited tumor growth in murine models. Immunohistochemistry results further revealed that Ori downregulated phospho-EGFR, MMP-12, and CIP2A in vivo. These findings indicated that Ori can inhibit the proliferation, invasion, and migration of gefitinib-resistant NSCLC cells by suppressing EGFR/ERK/ MMP-12 and CIP2A/PP2A/Akt signaling pathways. Thus, Ori may be a novel effective candidate to treat gefitinib-resistant NSCLC.
\end{abstract}

Correspondence to: Professor Ying Liu, Department of Biochemistry, School of Basic Medical Sciences, Hubei University of Medicine, Shiyan, Hubei 442000, P.R. China

E-mail: ying_liu1002@163.com

Dr Jiu Wang, School of Pharmaceutical Sciences, Hubei University of Medicine, Shiyan, Hubei 442000, P.R. China

E-mail: zhiziangel@163.com

*Contributed equally

Key words: oridonin, gefitinib-resistant non-small cell lung cancer, invasion, MMP-12, CIP2A, murine model

\section{Introduction}

Lung cancer is the most frequent cancer-related cause of death worldwide, and more than one-quarter of cancer patients die from lung cancer annually. An estimated 1.8 million new lung cancer cases were recorded in 2012, and these cases accounted for approximately $13 \%$ of the total cancer cases (1). Despite the lower prevalence of smoking in China, lung cancer rates among Chinese women (20.4 cases per 100,000 women) are higher than those among European women. Lung cancer treatments, including surgery, platinum doublet therapy, radiation therapy, and targeted therapy, depend on histological type and stage upon diagnosis; these treatment regimens account for $15 \%$ of the 5 -year overall survival rate of patients in all stages combined (2). Non-small cell lung cancer (NSCLC) accounts for the majority $(80 \%)$ of all lung cancer cases (3). The epidermal growth factor receptor-tyrosine kinase inhibitors (EGFR-TKIs) gefitinib and erlotinib elicit remarkable therapeutic effects against NSCLCs, with EGFR-activating mutations, such as exon 19 deletions and L858R point mutations. However, cancer cells commonly develop TKI resistance; as a result, tumor recurrence occurs (4). Therefore, acquired EGFR-TKI resistance should be clinically resolved. Differences between gefitinib responders and non-responders have been revealed in terms of the frequency of secondary mutation in exon 20 of EGFR T790M. EGFR Thr790 is an important amino acid residue accounting for the specificity of an inhibitor in the ATP binding pocket behind the ATP binding cleft; nevertheless, the substitution of Thr790 with Met increases the ATP affinity and reduces the potency of any ATP-competitive kinase inhibitor through which the T790M mutation confers drug resistance (5). T790M mutation has also been discovered in up to $50 \%$ of cases exhibiting acquired resistance (6). Therefore, strategies to overcome EGFR-TKI resistance should be developed to prolong the survival time of lung cancer patients.

Efforts to block signaling from the second mutant EGFR with small-molecule inhibitors has led to the conceptual introduction of experimental, irreversible EGFR TKIs that function primarily by covalently attaching to the cysteinyl-797 
residue in the pocket of the EGFR-kinase domain (7). Smallmolecule inhibitors, such as HKI-272, BIBW2992 (Afatinib), and PF00299804, have been mainly used to reverse the acquired resistance to EGFR T790M mutation in clinics and laboratories; these inhibitors have also demonstrated modest efficacy in preclinical in vitro model studies (8). However, in T790M EGFR-harboring cells, the EGFR inhibition induced by currently available second-generation EGFR-TKIs is insufficient to physiologically prevent the emergence of cells that remain dependent on EGFR signaling (8). Thus, multitargeted third-generation EGFR-TKIs have been designed and have provided clinical advantages (9). Furthermore, novel multi-targeted drugs that can overcome EGFR-TKI resistance should be identified and developed to prolong the overall survival time of NSCLC patients.

Protein phosphatase 2A (PP2A) is a tumor suppressor enzyme that regulates cell homeostasis by counteracting most of the kinase-driven intracellular signaling pathways (10). The aberrant expression, mutation, and somatic alteration of the PP2A scaffold and regulatory subunits are frequently found in human breast, lung, colon, and skin cancers (11). Therefore, the reactivation of $\mathrm{PP} 2 \mathrm{~A}$ on the basis of its tumor suppressor properties is a potential therapeutic strategy to treat human cancer $(12,13)$. In malignant cellular growth, the cancerous inhibitor of protein phosphatase 2A (CIP2A) protein inhibits the PP2A activity of the oncogenic transcription factor c-Myc (14). Previous independent studies demonstrated that aberrant CIP2A overexpression is associated with tumor growth, apoptosis resistance, drug resistance, prognosis, and metastasis in many human malignancies, including leukemia $(15,16)$, gastric $(17)$, breast $(18)$, tongue $(19)$, head and neck (14), ovarian (20), and lung (21) cancers. High CIP2A expression is also considered as a poor prognostic factor of lung cancer (22). Thus, targeting CIP2A protein is a potential strategy to treat cancer by reactivation of PP2A.

Oridonin (Ori, Fig. 1A), a bitter tetracyclin diterpenoid compound, has been isolated from Rabdosia rubescens, Isodon japonicus Hara, and I. trichocarpus, which are widely distributed in China, Japan, and Korea (23). Ori displays a potent anticancer activity against a wide range of cancer cell types, including cells from patients with prostate and breast cancers, NSCLC, acute leukemia, glioblastoma multiforme, and human melanoma (23-27). This study investigated the antitumor effects and possible mechanisms of Ori against gefitinib-resistant EGFR ${ }^{\mathrm{L} 858 \mathrm{R} / \mathrm{T} 790 \mathrm{M}}$-driven NSCLC.

\section{Materials and methods}

Reagents. Oridonin (Ori) with a purity of up to $98 \%$ was purchased from Shanghai Yuanye Bio-Technology Co., Ltd. Ori was dissolved in DMSO (Sigma) at a stock solution of $100 \mathrm{mM}$ and stored at $-20^{\circ} \mathrm{C}$. Docetaxel (DTX) was provided by Shanghai Jinhe Bio-Technology Co., Ltd. (Shanghai, China).

Cell culture. Human NSCLC cell lines A549 and NCI-H1975 (H1975) were obtained from American Type Culture Collection (ATCC). A549 cells were cultured in Dulbecco modified Eagle medium (DMEM). H1975 cells were cultured in RPMI-1640 medium. DMEM and RPMI-1640 medium were supplemented with $10 \%$ fetal bovine serum (FBS) (Hyclone),
$100 \mathrm{U} / \mathrm{ml}$ penicillin, and $100 \mu \mathrm{g} / \mathrm{ml}$ streptomycin and cultured in a humidified atmosphere with $5 \% \mathrm{CO}_{2}$ at $37^{\circ} \mathrm{C}$.

Cytotoxic assay and cell viability. Cells were seeded into 96-well plate and pre-cultured for $24 \mathrm{~h}$, then treated with Ori for $24 \mathrm{~h}$. Cell cytotoxicity was determined by MTT assay. The absorbance was measured at $570 \mathrm{~nm}$ by Automated Microplated Reader (Bio-Tek, Winooski, VT, USA), and the cell death rate was calculated as follows: Inhibition Rate $(\%)=$ (average $\mathrm{A}_{570}$ of the control group - average $\mathrm{A}_{570}$ of the experimental group) / (average $\mathrm{A}_{570}$ of the control group - average $\mathrm{A}_{570}$ of the blank group) $\mathrm{x} 100 \%$. Cell viability was estimated by trypan blue dye exclusion (28).

Soft-agar colony formation assay. Cells were suspended in $1 \mathrm{ml}$ of RPMI-1640 containing $0.3 \%$ low-melting-point agarose (Amresco, Solon, OH, USA) and 10\% FBS, and plated on a bottom layer containing $0.6 \%$ agarose and $10 \%$ FBS in 6-well plate in triplicate. After 2 weeks, plates were stained with $0.2 \%$ gentian violet and the colonies were counted under a light microscope (29).

Invasion assay. An invasion assay was carried out using a 24-well plate (Corning). A polyvinyl-pyrrolidone-free polycarbonate filter ( $8 \mu \mathrm{m}$ pore size) (Corning) was coated with Matrigel (BD Biosciences). The lower chamber was filled with medium containing $20 \%$ FBS as chemoattractant. The coated filter and upper chamber were laid over the lower chamber. Cells (1x10 4 cells/well) were preincubated with Ori for $30 \mathrm{~min}$ at room temperature, and then cell suspension containing Ori was seeded onto the upper chamber wells. After incubation for $20 \mathrm{~h}$ at $37^{\circ} \mathrm{C}$, the filter was fixed and stained with $2 \%$ ethanol containing $0.2 \%$ crystal violet $(15 \mathrm{~min})$. After being dried, the stained cells were enumerated under a light microscope at x10 objective. For quantification, the invaded stained cells on the other side of the membrane were extracted with $33 \%$ acetic acid. The absorbance of the eluted stain was determined at $570 \mathrm{~nm}$.

Wound healing assay. Cells $\left(4 \times 10^{5}\right.$ cells $\left./ 2 \mathrm{ml}\right)$ were seeded in a 6 -well plate and incubated at $37^{\circ} \mathrm{C}$ until 90 to $100 \%$ confluence. After the confluent cells were scratched with a $200 \mu$ l pipette tip, followed by washing with PBS, and then treated with Ori in a complete medium. After $24 \mathrm{~h}$ of incubation, the cells were fixed and stained with $2 \%$ ethanol containing $0.2 \%$ crystal violet powder (15 $\mathrm{min}$ ), and randomly chosen fields were photographed under a light microscope at $\mathrm{x} 4$ objective. The number of cells migrated into the scratched area was calculated.

Adhesion assay. Cells ( $5 \times 10^{4}$ cells/well) preincubated with Ori for $30 \mathrm{~min}$ at $37^{\circ} \mathrm{C}$ were seeded in a 96 -well plate coated with matrigel for $20 \mathrm{~min}$ at $37^{\circ} \mathrm{C}$. Unattached cells were removed by washing with PBS. Attached cells were fixed in $4 \%$ paraformaldehyde for $15 \mathrm{~min}$, stained with $0.02 \%$ crystal violet solution for $10 \mathrm{~min}$, and randomly chosen fields were photographed under a Leica DMI 400B microscope. Then, to quantify the number of attached cells, crystal violet was dissolved with $70 \%$ ethanol and OD was measured by microplate reader at $570 \mathrm{~nm}$, reference $405 \mathrm{~nm}$. The adhesion cells were calculated as a percentage of adhesion. 
Western blotting. Cell pellets were lysed in RIPA buffer containing $50 \mathrm{mM}$ Tris $\mathrm{pH} 8.0,150 \mathrm{mM} \mathrm{NaCl}, 0.1 \%$ SDS, $0.5 \%$ deoxycholate, $1 \%$ NP-40, 1 mM DTT, $1 \mathrm{mM} \mathrm{NaF}, 1 \mathrm{mM}$ sodium vanadate, $1 \mathrm{mM}$ PMSF (Sigma), and $1 \%$ protease inhibitors cocktail (Merck). Protein extracts were quantitated and loaded on 8 to $12 \%$ sodium dodecyl sulfate polyacrylamide gel, electrophoresed, and transferred to a PVDF membrane (Millipore). The membrane was incubated with primary antibody, washed, and incubated with horseradish peroxidase (HRP)-conjugated secondary antibody (Pierce). Detection was performed by using a chemiluminescent Western detection kit (Cell Signaling Technology). The antibodies used were anti-CIP2A, anti-ERK2, anti-phospho-Akt (Ser473), anti-Akt (Santa Cruz Biotechnology), anti-phospho-ERK1/2 (Thr202/ Tyr204), anti-EGFR (L858R), anti-phospho-EGFR (Y1173), anti-PP2Ac (Cell Signaling Technology), anti-MMP-12 (Proteintech), anti-MMP-2 (Epitomics), and anti-GAPDH (Sangon Biotech Co., Ltd., AB10016) antibodies.

Gelatin zymography. H1975 cells were seeded in 6-well plates and allowed to grow to $80 \%$ confluency. The cells were then maintained in serum-free medium for $12 \mathrm{~h}$ prior to designated treatments with Ori for $24 \mathrm{~h}$. Conditioned medium was then collected, cleared and mixed with $5 \mathrm{X}$ SDS loading buffer, and subjected to electrophoresis on a $10 \%$ SDS-PAGE gel containing $0.1 \%$ gelatin. After electrophoresis, the gels were washed in renaturing buffer $(\mathrm{pH} \mathrm{7.5,2.5 \%}$ Triton $\mathrm{X}-100)$ for $30 \mathrm{~min}, 4$ times, and equilibrated in developing buffer $(50 \mathrm{mM}$ Tris- $\mathrm{HCl} \mathrm{pH} \mathrm{7.5,} 10 \mathrm{mM} \mathrm{CaCl}_{2}$, and $1 \mathrm{mM} \mathrm{ZnCl}_{2}$ ) for $30 \mathrm{~min}$ and finally incubated in fresh developing buffer at $37^{\circ} \mathrm{C}$ for $24 \mathrm{~h}$ to allow digestion of the gelatin. The gelatinolytic activity of MMPs was visualized by staining the gels with $0.5 \%$ Coomassie blue R-250 in $45 \%$ methanol, $10 \%$ acetic acid and destained with $45 \%$ methanol, $10 \%$ acetic acid until clear bands suggestive of gelatin digestion appeared.

RNA preparation and semi-quantitative PCR. The total RNA of the cells was isolated using the TRIzol Reagent (Invitrogen) and the phenol-chloroform extraction method according to the manufacturer's instruction. Total RNA $(2 \mu \mathrm{g})$ was annealed with random primers at $65^{\circ} \mathrm{C}$ for $5 \mathrm{~min}$. The cDNA was synthesized using a 1st-STRAND cDNA Synthesis kit (Fermentas). For PCR amplification, primers are as follows: GAPDH, forward primer: 5'-TCACCAGGGCTGCTTTTA-3', reverse primer: 5'-AAGGTCATCCCTGAGCTGAA-3'; MMP-12 forward primer: 5'-TTGTTCCTCACTGCTGTTCAC-3'; reverse primer: 5'-GTCCATCATCTGTCTCCTTTC-3'.

AP-1 luciferase reporter assay. H1975 cells were seeded in 12 -well culture plates. At a confluency of $70 \%$, cells were transfected with the pAP-1-Luc plasmids (Beyotime Institute of Biotechnology) using Lipofectamine 3000 (Invitrogen) according to manufacturer's instruction. After transfection for $4 \mathrm{~h}$, the cells were treated with Ori for $20 \mathrm{~h}$. Firefly luciferase activities were assayed using the Luciferase Assay System (Promega) according to the manufacturer's instructions.

Chromatin immunoprecipitation (ChIP) assay. H1975 cells treated with Ori for $24 \mathrm{~h}$ were processed for ChIP assay using a ChIP-IT ${ }^{\circledR}$ Express Enzymatic Shearing kit (Active
Motif). Briefly, immunoprecipitation was performed with anti-c-Fos (component of AP-1, Cell Signaling Technology) or rabbit IgG as a control. The AP-1 binding site of MMP-12 promoter was detected by real-time PCR using the following primers: 5'-GCTAATTGATCCATTGT-3' (forward) and 5'-TCTAGCCTAAGTTCC-3' (reverse).

PP2A activity assay. PP2A immunoprecipitation phosphatase assay kit (Upstate Biotechnology, Temecula, CA, USA) was used to measure phosphate release as an index of phosphatase activity according to the manufacturer's instructions. Briefly, $100 \mu \mathrm{g}$ of protein isolated from cells was incubated with $4 \mu \mathrm{g}$ anti-PP2A monoclonal antibody overnight. $40 \mu \mathrm{l}$ of protein A agarose beads were added and the mixture was incubated at $4^{\circ} \mathrm{C}$ for $2 \mathrm{~h}$. Subsequently, the beads were collected and washed three times with $700 \mu 1$ of ice-cold TBS and one time with $500 \mu \mathrm{l}$ of Ser/Thr Assay buffer. The beads were further incubated with $750 \mathrm{mM}$ phosphopeptide in assay buffer for $10 \mathrm{~min}$ at $30^{\circ} \mathrm{C}$ with constant agitation. Malachite Green Phosphate Detection Solution $(100 \mu \mathrm{l})$ was added and the absorbance at $650 \mathrm{~nm}$ was measured on a microplate reader (30).

Drug combination assay. Drug combination is widely used in cancer treatment to achieve synergistic therapeutic effect and overcome drug resistance in clinic. To estimate the effect of Ori and DTX combination, the combination index (CI) was calculated by the Chou-Talalay equation (29). H1975 cells were seeded in 96-well plates. Drugs were added alone or together at indicated concentration. The inhibition effect was measured by MTT assay as mentioned above. The formula of CI = (D) Ori/(Dx) Ori + (D)DTX/(Dx)DTX ((D)Ori and (D)DTX: the doses of compounds Ori and DTX, respectively, necessary to produce the same effect in combination. Dx: the dose of one compound alone required producing an effect). With this formula and assistance of CalcuSyn software (version 2.1), the combined effects of the two compounds can be assessed as follows: $\mathrm{CI}<1$ indicates synergism; $\mathrm{CI}=1$ indicates additive effect; and $\mathrm{CI}>1$ indicates antagonism.

Human NSCLC xenograft experiments. Equal number of female and male nude immunodeficient mice (nu/nu), 6-8 weeks old, were purchased from Hunan SJA Laboratory Animal Co., Ltd., and maintained and monitored in a specific pathogen-free environment. All animal studies were conducted according to protocols approved by the Hubei University of Medicine Animal Care and Use Committee, complying with the rules of Regulations for the Administration of Affairs Concerning Ex-Perimental Animals (Approved by the State Council of China). The mice were injected subcutaneously with NSCLC H1975 cells $\left(2.5 \times 10^{6}\right)$ suspended in $100 \mu \mathrm{l}$ RPMI-1640 medium into the right flank of each mouse. Treatments were started when the tumors reached a palpable size. Mice were randomly divided into three groups and treated with Ori (30 mg/kg, n=8), Gefitinib (30 mg/kg, n=7) or vehicle control $(n=7)$ for 3 weeks. Caliper measurements of the longest perpendicular tumor diameters were performed twice a week to estimate the tumor volume, using the following formula: $4 \pi / 3 \times(\text { width } / 2)^{2} \times($ length $/ 2)$, representing the 3-dimensional volume of an ellipse. Animals were sacrificed when tumors reached $1.5 \mathrm{~cm}$ or if the mice appeared moribund to prevent 
A

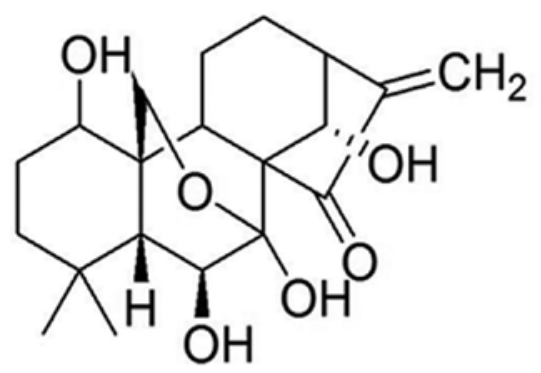

C

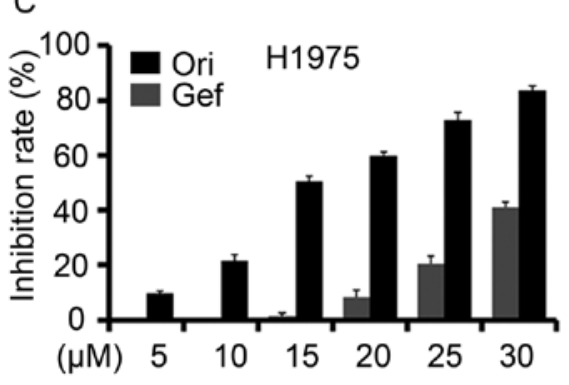

E

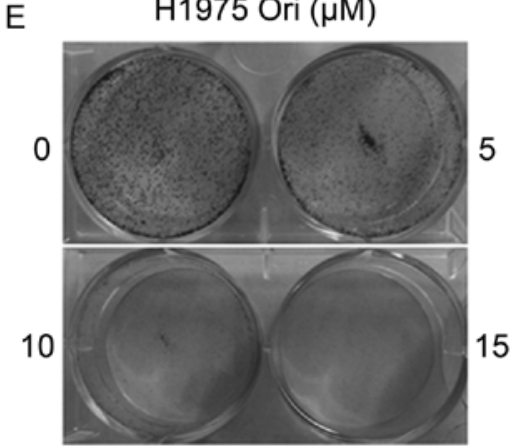

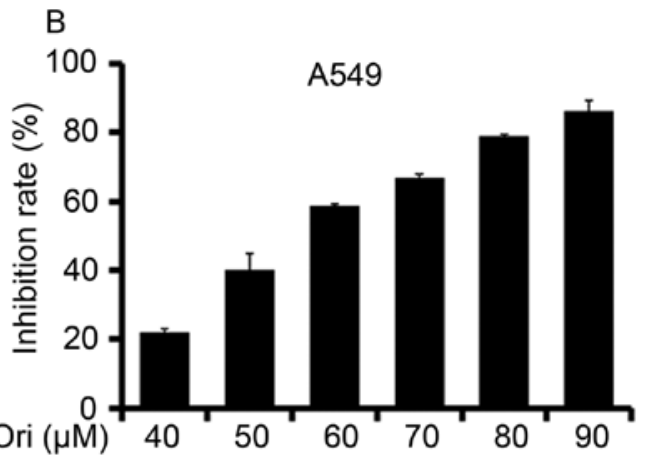

D
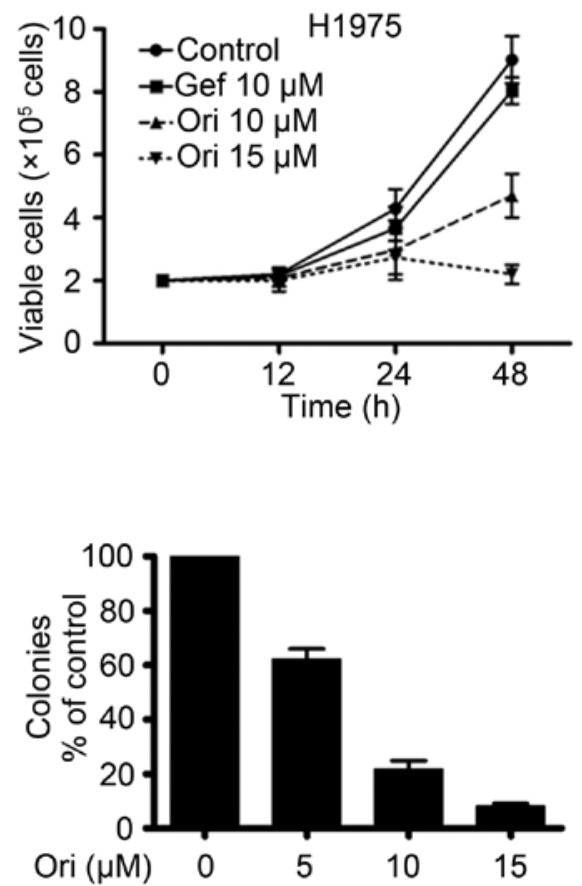

Figure 1. Ori inhibits A549 and H1975 NSCLC cells. (A) Chemical structure of Ori. (B and C) The inhibitory effects of Ori on A549 and H1975 cells analyzed by MTT assay. Ori, oridonin; Gef, gefitinib. (D) Inhibitory effects of Ori on cell viability of H1975 cells assayed by trypan blue exclusion assay. (E) The colony formation assays of $\mathrm{H} 1975$ cells treated with Ori at indicated concentration.

unnecessary morbidity to the mice. At the time of sacrifice, tumors were excised for immunohistochemistry.

Immunohistochemistry of tissues. Formalin-fixed, paraffin-embedded tissues from mice were selected for immunohistochemical examination by using an indirect immunoperoxidase method. The antibodies used for immunohistochemical staining were pEGFR, CIP2A, and MMP-12.

Statistical analysis. All experiments were repeated at least three times and the data are presented as the mean \pm SD unless noted otherwise. Differences between data groups were evaluated for significance using Student t-test of unpaired data or one way analysis of variance and Bonferroni post-test. P-values $<0.05$ indicate statistical significance.

\section{Results}

Ori inhibits A549 and H1975 NSCLC cells. A549 and H1975 cells were seeded in 96-well plates for $24 \mathrm{~h}$ and then treated with different Ori concentrations (Fig. 1B and C). After $24 \mathrm{~h}$, cell viability was evaluated through an MTT assay in accordance with the manufacturer's protocol. The absorbance at $570 \mathrm{~nm}$ was determined by using an automated microplate reader. Ori exerted moderate cytotoxicity against the A549 and $\mathrm{H} 1975$ cells with $\mathrm{IC}_{50}$ of 55.91 and $15.53 \mu \mathrm{M}$, respectively (Table I). Trypan blue exclusion assay revealed that Ori rapidly reduced the number of viable H1975 cells (Fig. 1D) in a doseand time-dependent manner. We also investigated the effect of Ori on cell colony formation and found that Ori significantly inhibited the clonogenic ability of H1975 (Fig. 1E). These results suggested that Ori inhibited the anchorage-dependent (cell proliferation) and anchorage-independent (colony formation) growth of H1975 cells.

Ori inhibits invasion, migration, and adhesion of H1975 cells. We determined whether Ori inhibited the invasive behavior of H1975 cells. An invasion assay was performed using Matrigel-coated 24-well microchemotaxis chambers in the presence of Ori. Fig. 2A shows that Ori (0-20 $\mu \mathrm{M})$ markedly 

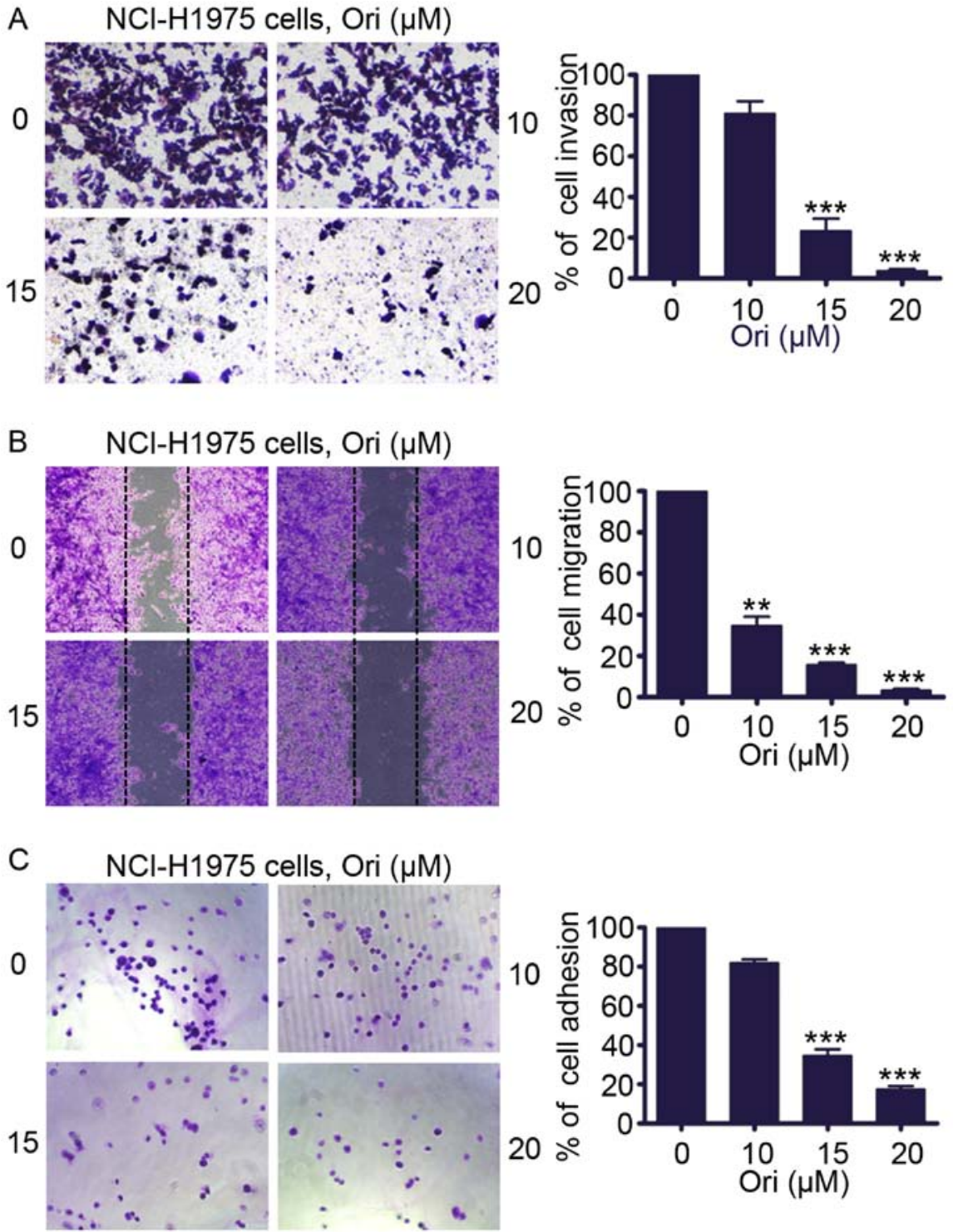

Figure 2. Ori inhibits invasion, migration, and adhesion of H1975 cells. (A) Invasion assay was carried out using modified 24-well microchemotaxis chambers. Then randomly chosen fields were photographed (x100), and the number of cells migrated to the lower surface was calculated as a percentage of invasion. Data are shown as the mean \pm SD of three independent experiments by analysis of Student's t-test. ${ }^{* * *} \mathrm{P}<0.001$ vs. $0 \mu \mathrm{M}$. (B) Confluent cells were scratched and then treated with Ori in a complete medium for $24 \mathrm{~h}$. The number of cells migrated into the scratched area was photographed (x40) and calculated as a percentage of migration. Data are shown as the mean $\pm \mathrm{SD}$ of three independent experiments by analysis of Student's t-test. ${ }^{* *} \mathrm{P}<0.01 ;{ }^{* * *} \mathrm{P}<0.001 \mathrm{vs} .0 \mu \mathrm{M}$. (C) Cells were seeded in a 96-well plate coated with matrigel and treated with Ori. Attached cells were photographed (x100) after crystal violet staining, and the number of attached cells was quantified by measuring OD. Data are shown as the mean $\pm \mathrm{SD}$ of three independent experiments. ${ }^{* * *} \mathrm{P}<0.001 \mathrm{vs.} 0 \mu \mathrm{M}$.

Table I. The $\mathrm{IC}_{50}$ of Ori on lung cancer cell lines.

\begin{tabular}{lcc}
\hline Cell lines & A549 & NCI-H1975 \\
\hline $\mathrm{IC}_{50}(\mu \mathrm{M})$ & $55.91 \pm 5.43$ & $15.53 \pm 3.57$ \\
\hline
\end{tabular}

The cells were treated with Ori at various concentrations for $24 \mathrm{~h}$, the cell cytotoxicity was analyzed by MTT assay, and the $\mathrm{IC}_{50}$ was calculated using CalcuSyn (version 2.1). Values shown are means \pm SD of quadruplicate determinations.

suppressed H1975 cell invasion. To explore the effect of Ori on migration, we treated the $\mathrm{H} 1975$ cells with Ori $(0-20 \mu \mathrm{M})$ and determined cell migration after $24 \mathrm{~h}$. Fig. 2B shows that
Ori significantly and dose-dependently reduced H1975 cell migration. We evaluated the effect of Ori on cell adhesion. Fig. 2C illustrates that Ori also inhibited the adhesion of H1975 cells onto the Matrigel in a concentration-dependent manner compared with the untreated control cells. These results suggested that Ori exerted an anti-invasive behavior toward lung cancer at moderate concentrations.

Ori suppresses EGFR and ERK1/2 signaling in H1975 cells. EGFR and extracellular regulated protein kinases (ERK) play important roles in the proliferation and invasion of NSCLC cells (31). Ori can dose-dependently reduce the phosphorylation levels of EGFR and ERK without causing evident changes in the total EGFR and total ERK expression levels in H1975 cells (Fig. 3A and B). Considering that MMP-12, which can be regulated by ERK1/2 pathway, plays an important role in 
A

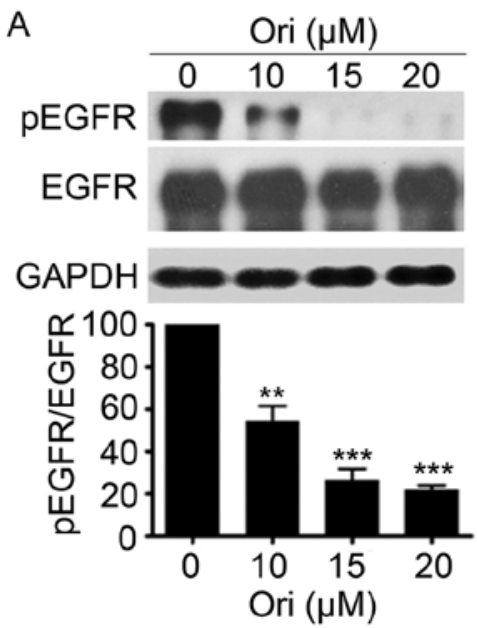

D
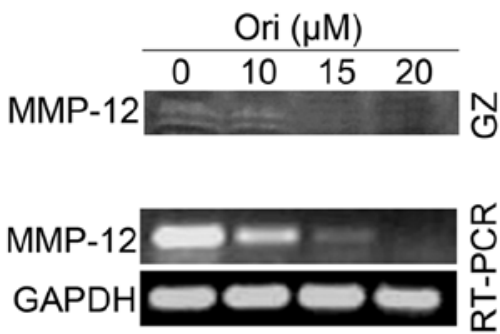

B
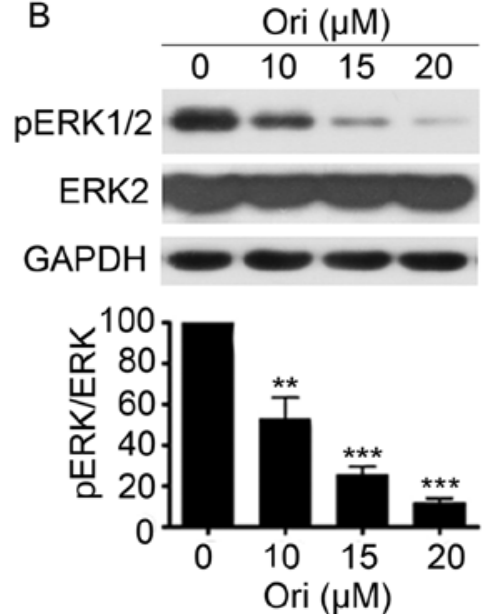

E

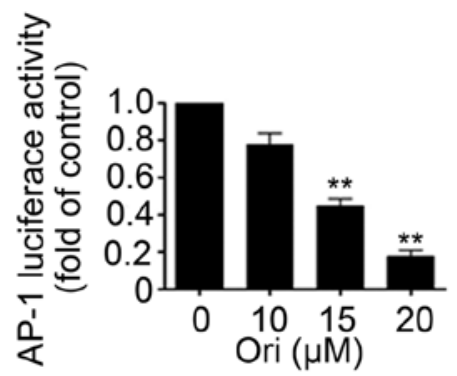

C

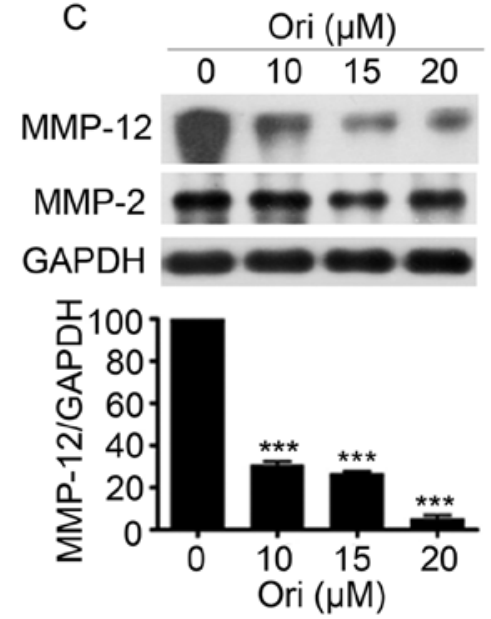

F

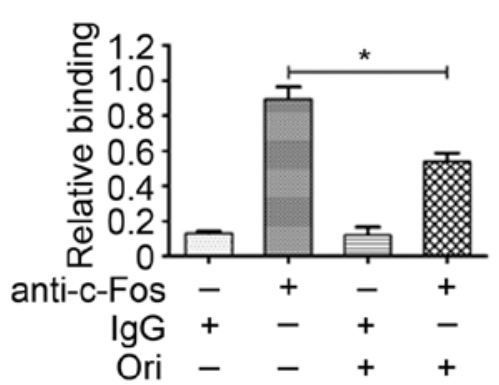

Figure 3. Ori suppresses EGFR and ERK1/2 signaling in H1975 cells. H1975 cells were treated with increasing concentrations of Ori for 24 h. (A-C) Western blot was performed using the antibodies indicated. GAPDH was used as the loading control. The densitometry analysis of every factor was performed, normalized with the corresponding GAPDH content. Values are presented as mean $\pm \mathrm{SD}$ of three independent experiments; ${ }^{*} \mathrm{P}<0.05,{ }^{* *} \mathrm{P}<0.01$ and ${ }^{* * *} \mathrm{P}<0.001$ compared with the control group. (D) Upper panel: The activity of MMP-12 was assessed using the concentrated conditioned medium (CM) by gelatin zymography (GZ). The concentration of CM protein was measured by Bradford assay. Lower panel: MMP-12 gene expression was detected by RT-PCR analysis (RT-PCR). GAPDH was used as a housekeeping gene. (E) H1975 cells were transfected with the AP-1 luciferase reporter construct for 4 h and then treated with Ori. Luciferase activity was measured using the Luciferase assay system. (F) Ori prevented binding of c-Fos to MMP-12 promoter. Chromatins were prepared from H1975 cells incubated with or without $15 \mu \mathrm{M}$ Ori. ChIP was carried out by using anti-c-Fos antibody, and the amplification was performed by SYBR Green real-time PCR.

the migration and invasion of cancer cells (32), we examined the expression and gelatinolytic activity of MMP-12 in H1975 cells exposed to different Ori concentrations (Fig. 3C and D). The results showed that the gelatinolytic activity and expression levels of MMP-12 were significantly reduced in the Ori-treated H1975 cells in a dose-dependent manner compared with the control groups. AP-1, which is regulated by MAPKs, such as ERK, JNK, and P38 kinase, is a critical transcription factor that activates MMP-12 transcription (33). We also examined the effect of Ori on the transcriptional activity of AP-1 through luciferase reporter assay and found that 15 and $20 \mu \mathrm{M}$ of Ori significantly inhibited AP-1 transcription activity (Fig. 3E). Chromatin immunoprecipitation (ChIP) assays also revealed that $15 \mu \mathrm{M}$ of Ori inhibited the DNA binding of c-Fos (component of AP-1) to MMP-12 promoter (Fig. 3F). These results indicated that Ori can significantly suppress the invasive behavior (invasion, migration, and adhesion) of H1975 cells via the EGFR/ERK/AP-1/MMP-12 signaling pathway.

Ori inhibits CIP2A and regulates the PP2A/Akt pathway. The Akt pathway controls tumor cell growth, survival, progres- sion, apoptosis, invasion, and metastasis, and Akt is a critical locus of cancer multidrug resistance and fragility (34). Ori selectively targets the Akt signaling pathway and inhibits apoptosis of cervical carcinoma HeLa cell line (35). Therefore, we investigated the effect of Ori on Akt phosphorylation in H1975 cells. Our results showed that the phosphorylation level of Akt was dose-dependently downregulated, and the total Akt level did not evidently change in the Ori-treated H1975 cells compared with the control group (Fig. 4A). Furthermore, we determined the changes in the expression of PP2A, which is an upstream phosphatase of Akt. The results suggested that Ori could upregulate the PP2Ac (catalytic subunit) expression level. To elucidate the mechanism of Ori-induced PP2Ac upregulation, we examined the PP2A activity and found that this activity was upregulated in the Ori-treated H1975 cells compared with that in the control group, which is possibly one of the reasons leading to the Ori-mediated downregulation of Akt phosphorylation (Fig. 4B). Moreover, CIP2A is an endogenous inhibitory protein of $\mathrm{PP} 2 \mathrm{~A}$, which demonstrates cancer-promoting profile in NSCLC (21). We subsequently detected the CIP2A expression and found that Ori significantly downregulated the expression of the CIP2A protein (Fig. 4C). 

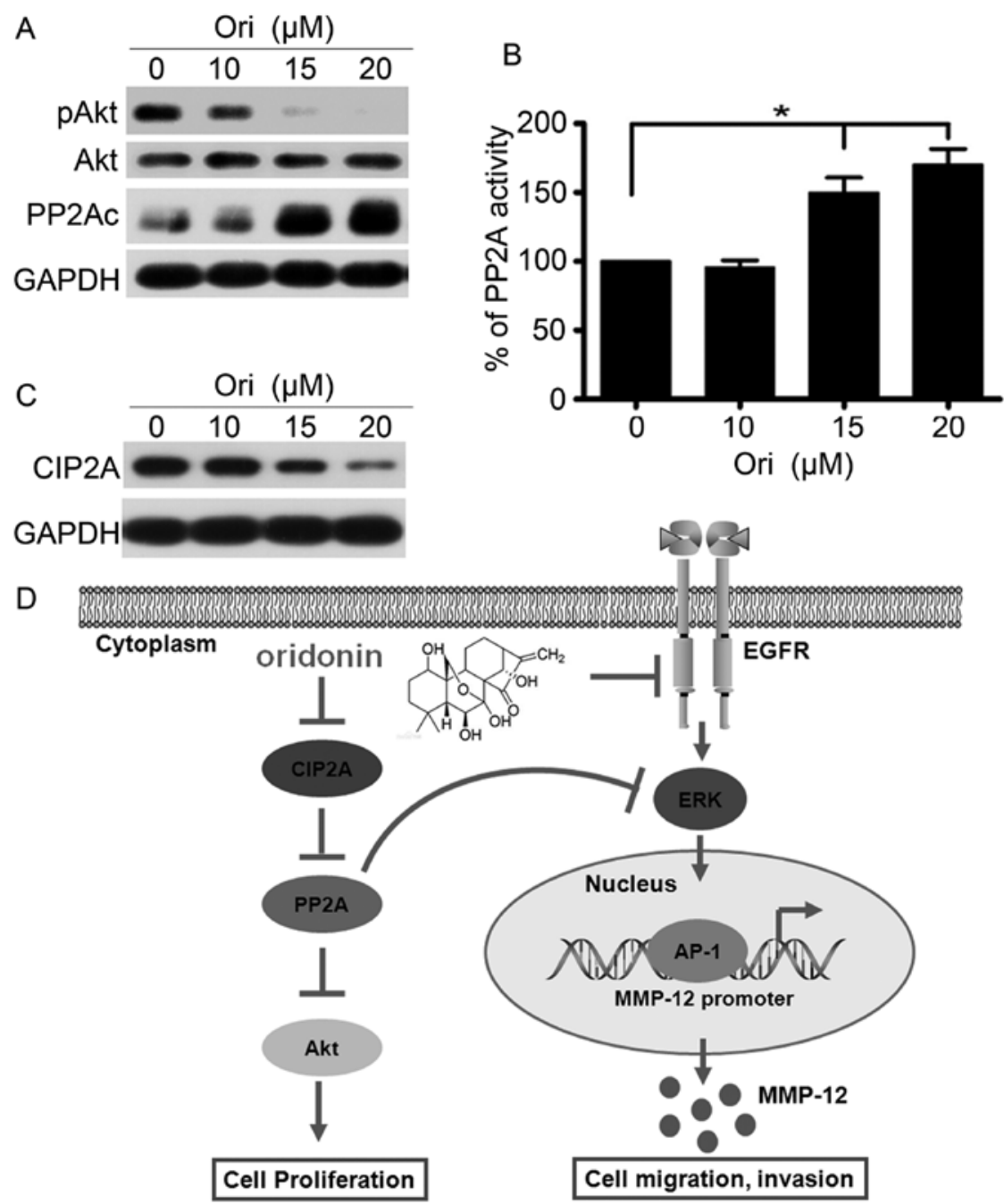

Figure 4. Ori inhibits CIP2A and regulates the PP2A/Akt pathway. (A) H1975 cells were treated with increasing concentrations of Ori for $24 \mathrm{~h}$. Western blotting was performed using the antibodies indicated. GAPDH was used as the loading control. (B) H1975 cells were treated with increasing concentrations of Ori for 24 h. PP2A activity was measured by PP2A immunoprecipitation phosphatase assay. (C) H1975 cells were treated with increasing concentrations of Ori for $24 \mathrm{~h}$. Western blotting was performed using the antibodies indicated. GAPDH was used as the loading control. (D) Diagram of the signal pathway where Ori inhibits H1975 cell invasion and migration.

Thus, Ori elicits an inhibitory effect on H1975 cells by regulating the CIP2A/PP2A/Akt signal cascade.

On the basis of these results, we concluded that Ori inhibited gefitinib-resistant NSCLC growth and cell invasion by inhibiting the EGFR/ERK/AP-1/MMP-12 signaling pathway and the CIP2A/PP2A/Akt signal cascade (Fig. 4D).

Ori and docetaxel (DTX) synergistically inhibit H1975 cells. One or more drugs are commonly used in clinics to improve the therapeutic efficacy and reduce the side effects on patients and non-target tissues. Furthermore, an optimal combined treatment may reduce or postpone drug resistance. Microtubular-targeted chemotherapy agents, such as DTX, are among the most widely prescribed first- and second-line chemotherapeutic options for patients suffering from common malignancies, including lung cancer (36). Unfortunately, these malignancies usually develop primary resistance to DTX; thus, drug resistance poses an important clinical problem. We examined whether the combination of Ori and DTX synergistically inhibits the NSCLC treatment. We further chose the low-toxicity $(2.5$ and $5 \mu \mathrm{M})$ doses of Ori and DTX ( 4 and $8 \mathrm{nM})$ to detect (Fig. 5A). The combination of Ori and DTX elicited a greater effect on the H1975 cells than the sole treatment of DTX or Ori $(\mathrm{P}<0.05)$. We also analyzed the combination index $(\mathrm{CI})$ by using a formula assisted by CalcuSyn software (version 2.1) and found that the CIs were $<1$ (Fig. 5B, Table II). This finding indicated that Ori and DTX synergistically affected the H1975 cells. Western blot analysis further confirmed this synergistic effect and revealed that the combination of Ori and DTX reduced the expression levels of pEGFR, pERK, and MMP-12 (Fig. 5C). This combination also influenced the CIP2A/PP2A/ Akt signal cascade (Fig. 5D).

Ori inhibits tumor growth in murine models. To determine the antitumor effect of Ori on NSCLC in vivo, we subcutaneously inoculated $2.5 \times 10^{6} \mathrm{H} 1975$ cells in $100 \mu 1$ of RPMI-1640 medium in the right flank of nude mice to generate xenografted murine models. Once the tumors grew to a measurable size, each group was administered with the vehicle control, gefitinib $(30 \mathrm{mg} / \mathrm{kg})$, and Ori $(30 \mathrm{mg} / \mathrm{kg}) 5$ times per week for 21 days. The tumor-bearing mice were humanely sacrificed when their tumors reached $1.5 \mathrm{~cm}$ in diameter or when paralysis or 
A

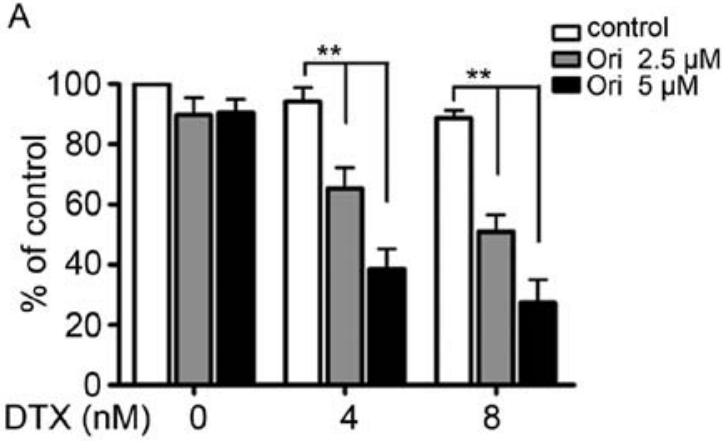

C

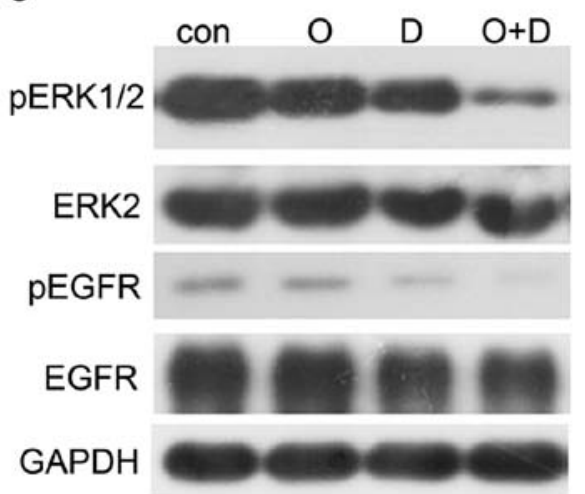

B

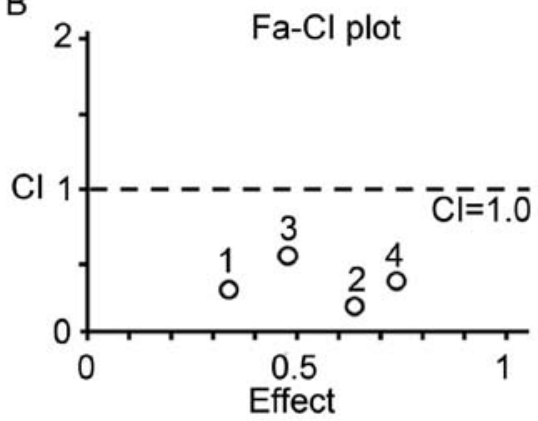

D

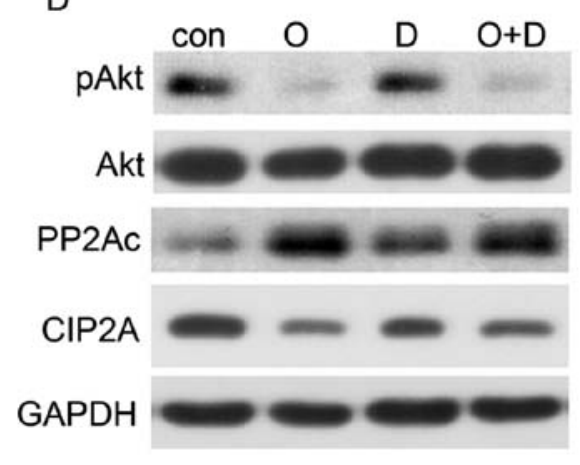

Figure 5. Ori and docetaxel (DTX) synergistically inhibit H1975 cells. (A-B) H1975 cells were treated for 24 h with DTX (0, 4 , 8 nM) in the presence of Ori at $0,2.5,5 \mu \mathrm{M}$. MTT assay was used to test the proliferation of cells (A), and the combined effects were evaluated by the Chou-Talay method and Calcusyn software (B). ${ }^{*} \mathrm{P}<0.05,{ }^{* *} \mathrm{P}<0.001$. (C-D) H1975 cells were cultured with control media (Con), Ori (O, $\left.5 \mu \mathrm{M}\right)$, DTX (D, 8 nM), or Ori (5 $\left.\mu \mathrm{M}\right)$ plus DTX (8 nM) $(\mathrm{O}+\mathrm{D})$ for $24 \mathrm{~h}$. Cells were then lysed and subjected to western blotting using indicated antibodies.

major compromise in their quality of life occurred. We found that Ori efficiently repressed tumor growth compared with the vehicle control or gefitinib $(\mathrm{P}<0.01$; Fig. $6 \mathrm{~A}$ and $\mathrm{B})$. Ori treatment also significantly reduced the tumor weight of the mice (Fig. 6C). In addition, Ori treatment did not significantly reduce the body weight of the mice. This finding suggested that Ori did not cause evident side effects (Fig. 6D). All of the mice were euthanized, and the tumor specimens were examined through immunohistochemistry; the results showed that the expression levels of p-EGFR, MMP-12, and CIP2A were downregulated in the Ori-treated groups (Fig. 6E). Therefore, Ori could be a potential therapeutic agent against gefitinibresistant NSCLC.

\section{Discussion}

Ori elicits an anti-proliferative effect on lung cancer cell lines in vitro and in vivo $(26,37)$. However, the antitumor effects of Ori on gefitinib-resistant lung cancer cells remain poorly understood. This study is the first to demonstrate that Ori inhibited the metastasis of gefitinib-resistant lung cancer cells in vitro by downregulating the EGFR/ERK-mediated MMP-12 expression, by reactivating PP2A, and by downregulating CIP2A. These data strongly suggested the possible beneficial effects of Ori on patients suffering from gefitinib-resistant lung cancer.

Over $90 \%$ of deaths caused by solid tumors are attributed to tumor metastasis (38). Thus, therapeutic strategies to suppress or prevent cancer metastasis will greatly improve the survival of cancer patients. Our data suggested that Ori remarkably
Table II. Ori and DTX combination index (CI) values.

\begin{tabular}{lccc}
\hline Ori $(\mu \mathrm{M})$ & DTX $(\mathrm{nM})$ & Effect & CI (Ori+DTX) \\
\hline 2.5 & 4 & 0.32 & 0.32 \\
2.5 & 8 & 0.62 & 0.22 \\
5 & 4 & 0.49 & 0.52 \\
5 & 8 & 0.73 & 0.39 \\
\hline
\end{tabular}

H1975 cells were treated with Ori and DTX combined or alone with indicated concentrations for $24 \mathrm{~h}$, the cytotoxicity was analyzed by MTT assay, and the CI values were calculated using CalcuSyn software (version 2.1). The effect was the combined inhibition rate of Ori and DTX, and was calculated as follows: Effect $=\left(\right.$ average $A_{570}$ of the control group - average $\mathrm{A}_{570}$ of the experimental group) / (average A570 of the control group - average $\mathrm{A}_{570}$ of the blank group).

inhibited the invasive (Fig. 2A) and migratory (Fig. 2B) abilities of H1975 cells. In addition, the adhesion of cancer cells onto extracellular matrix (ECM) and their interactions are crucial steps during metastasis and invasion. Our result showed that Ori treatment remarkably inhibited cell adhesion onto matrigel (Fig. 2C).

Cell invasion and migration involve various growth factors, which bind to their receptors on the cell surface and then activate downstream signaling pathways; as a result, the cytoskeleton is reorganized and the cellular motility 
A

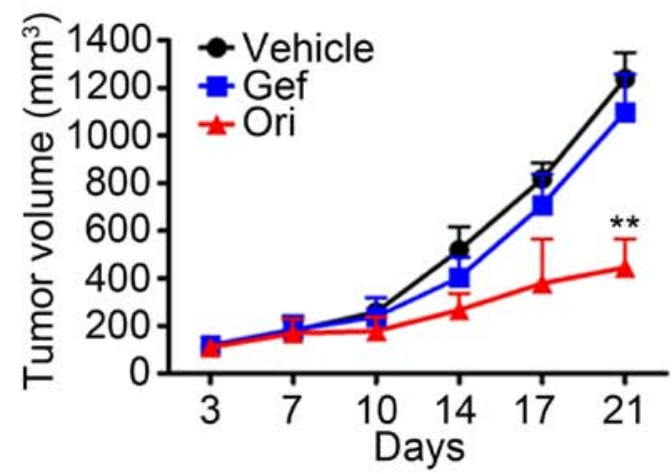

C

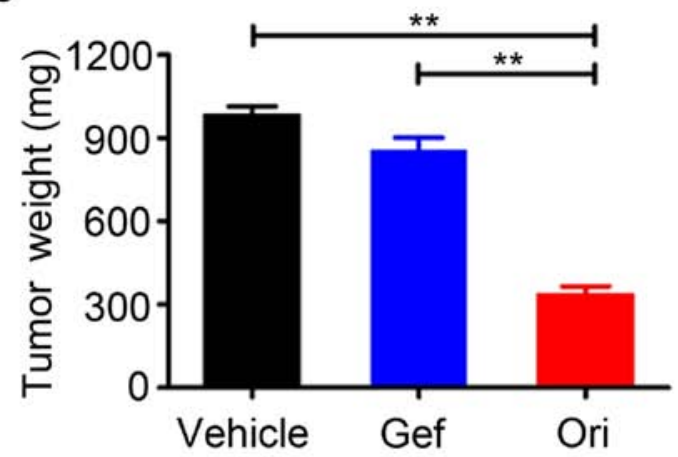

E

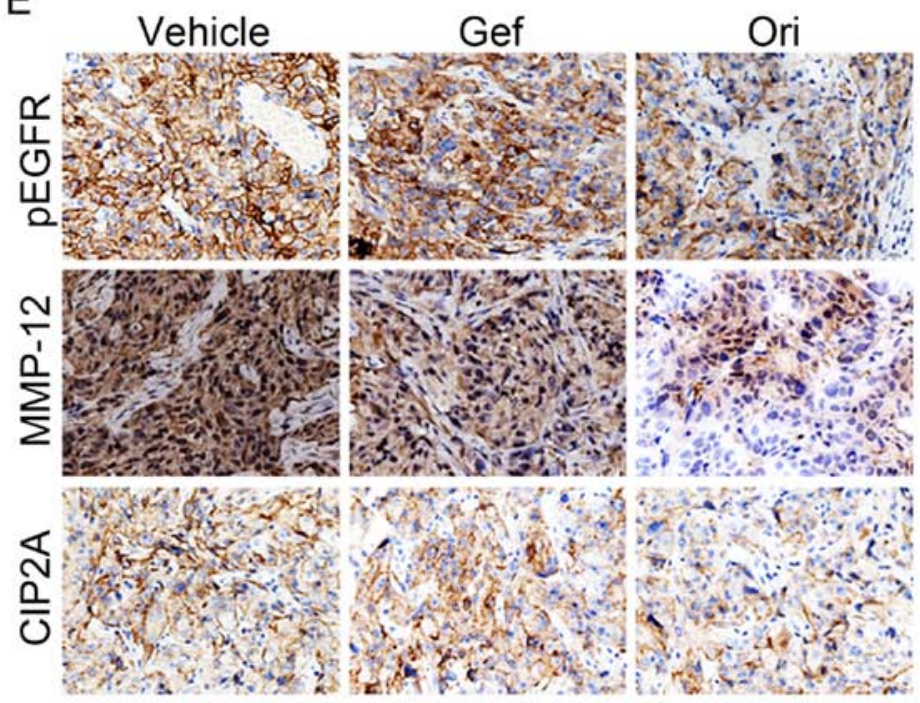

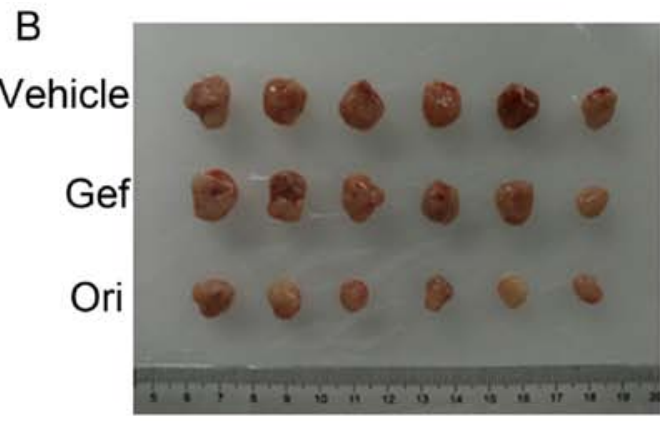

D

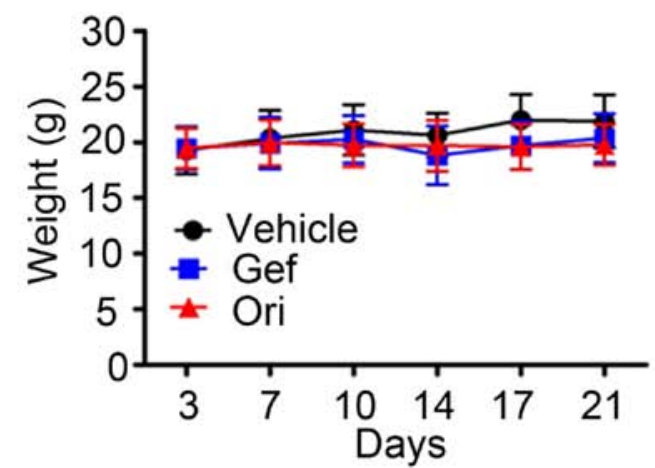

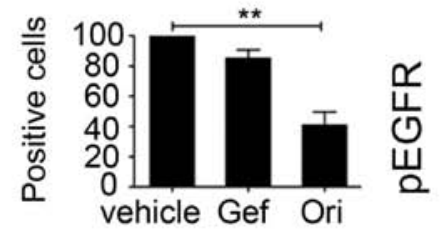
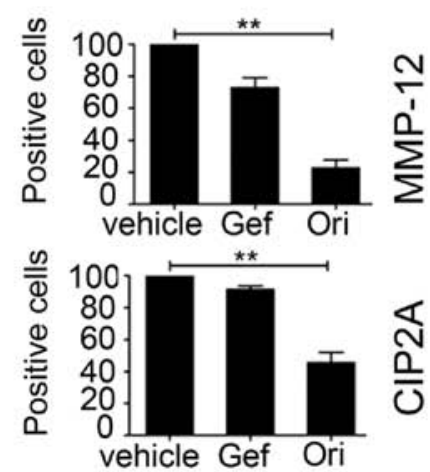

Figure 6. Ori inhibits tumor growth in murine models. (A) Murine models were treated with vehicle, gefitinib (Gef) or Ori and the tumor volumes were calculated twice a week. ${ }^{* *} \mathrm{P}<0.01$ vs. vehicle or Gef. (B) Images of xenograft tumors obtained from mice with different treatment after 3 weeks. (C) Weight of the tumor from each group taken out from the sacrificed mice at the end of the study ${ }^{* *} \mathrm{P}<0.01$ vs. vehicle or Gef. (D) Ori treatment did not affect the murine model body weight. (E) The expressions of p-EGFR, MMP-12, and CIP2A in xenograft tumors were analyzed by immunohistochemistry (original magnification of $\mathrm{x} 400$ ), and their expression levels were quantified in percentages of positive cells within 5 medium-power fields under microscope and shown in histograms; ${ }^{*} \mathrm{P}<0.05,{ }^{* *} \mathrm{P}<0.01$ compared with the control group.

machinery is stimulated (39). Aberrations in EGFR expression and downstream signaling pathways contribute to the progression, invasion, and maintenance of the malignant phenotype of many human cancers (40). We found that the phosphorylation level of EGFR remarkably decreased as the Ori concentrations increased. This finding suggested that Ori affected the H1975 cells possibly by suppressing the EGFR phosphorylation and the EGFR-mediated signaling pathway (Fig. 3A). We subsequently explored the signal transduction pathways that potentially mediate EGF signal transduction. ERK has been implicated in the control of diverse biological processes, such as cell proliferation, differentiation, and apoptosis; ERK also plays complementary function on cell survival. ERK is rapidly activated in cells stimulated by various mitogens or motogens, including EGF (41). This study found that Ori could inhibit ERK1/2 phosphorylation (Fig. 3B). Cancer invasion and migration are a multistep process involving many types of cell-cell interactions.

A critical step in tumor invasion and migration is the basement membrane degradation, which is catalyzed by proteolytic 
enzymes, such as matrix metalloproteinases (MMPs) and tissue inhibitor of metalloproteinases (TIMPs). MMPs comprise a multigene family, which includes more than 22 members. MMP-1, MMP-2, MMP-9, MMP-10, MMP-13, and MMP-14 are expressed in human lung cancer cells (42). MMP-2 and MMP-9 are the most studied MMPs in lung cancer; they are upregulated in locally invasive tumors and their expression is correlated with lung cancer invasiveness $(43,44)$. MMP-12 expression is also induced in human lung cancer during malignant transformation. However, limited information is available regarding the potential contribution of MMP-12 to NSCLC invasion. In addition, MMP-12 is regulated by the ERK pathway (32). Our study demonstrated that Ori treatment inhibited the gelatinolytic activity and expression of MMP-12 at protein and mRNA levels in H1975 cells compared with those in the untreated control cells (Fig. 3C and D). Therefore, MMP-12 is possibly an Ori-responsive mediator that likely degrades ECM; as a result, subsequent cancer migration and invasion may occur. With the activation of EGFR, the AP-1 signaling pathway in cancer cells is also activated (45). The activation of AP-1, which is found downstream of the ERK pathway, is involved in many pathological processes, such as inflammation, cancer cell adhesion, invasion, metastasis, and angiogenesis (40). Moreover, the MMP-12 promoter region contains a cis-regulatory element of two AP-1 binding sites. Thus, we investigated the effects of Ori on the AP-1 transcription activity and DNA binding to MMP-12 promoter; we found that Ori could inhibit the transcription activity (Fig. 3E) and DNA binding of AP-1 to MMP-12 promoter (Fig. 3F). Therefore, Ori is a novel anti-metastatic agent that may treat gefitinib-resistant NSCLC by suppressing the EGFR/ERK/MMP-12 pathway.

The Akt signaling pathway is one of the most critical cancer-promoting pathways and is frequently activated in many types of human cancers, including NSCLC. We then examined the p-Akt level in H1975 cells after Ori was administered; the results showed that the p-Akt expression was reduced in a dose-dependent manner (Fig. 4A). To clarify its mechanism, we evaluated the upstream Akt regulatory factors, including PP2A and EGFR. PP2A is a tumor suppressor protein that can exhibit protein phosphatase activity and can block the PI3K/Akt pathway; this protein also dephosphorylates and inactivates MEK1 and ERK family kinases (30). Our study also demonstrated that Ori treatment upregulated the PP2A activity in H1975 cells (Fig. 4B), and the PP2A upregulation inactivated the Akt and ERK pathways. As a result, the proliferation, migration, and invasion of in H975 cells were suppressed and the apoptosis of these cells were induced. To determine whether CIP2A, a critical upstream molecule of PP2A, is the target of Ori, we examined the CIP2A expression and found that the CIP2A expression was downregulated (Fig. 4C). CIP2A is also overexpressed and is related to poor clinical outcome in lung cancer. Several compounds targeting the CIP2A protein have shown potential activity in lung cancer in vivo and in vitro $(21,22)$. Our results indicated that the CIP2A/PP2A/Akt pathway may serve as an alternative mechanism underlying the effects of Ori.

Ori elicits enhanced cytotoxicity against H1975 cells when it is combined with the conventional agent DTX, a drug currently used in clinical trials to treat solid malignancies (Fig. 5). In a xenograft murine model of H1975, Ori signifi- cantly inhibited tumor growth, but the body weight of the mice remained unaffected (Fig. 6A-D). Our results also showed that Ori inhibited pEGFR, MMP-12, and CIP2A in vivo (Fig. 6E). Our results indicated that Ori directly affected not only the EGFR pathway but also the CIP2A/PP2A pathway. As a result, the growth of $\mathrm{H} 1975$ cells was suppressed. Therefore, Ori may be considered as a new antitumor agent to prevent and treat gefitinib-resistant lung cancer.

\section{Acknowledgements}

This work was supported by grants from the National Natural Sciences Foundation of China (81400157); grants from the Foundation for Innovative Research Team of Hubei University of Medicine (2014CXX05); the Natural Science Foundation of Hubei Provincial Department of Education (Q20152106); the Key Discipline Project of Hubei Province; the Faculty Development Grant 2014QDJZR08, 2015QDJZR16 from Hubei University of Medicine.

\section{References}

1. Torre LA, Bray F, Siegel RL, Ferlay J, Lortet-Tieulent J and Jemal A: Global cancer statistics, 2012. CA Cancer J Clin 65: 87-108, 2015

2. Zhang B, Jiao J, Liu Y, Guo LX, Zhou B, Li GQ, Yao ZJ and Zhou GB: Gefitinib analogue V1801 induces apoptosis of T790M EGFR-harboring lung cancer cells by up-regulation of the BH-3 only protein Noxa. PLoS One 7: e48748, 2012.

3. Siegel RL, Miller KD and Jemal A: Cancer statistics, 2015. CA Cancer J Clin 65: 5-29, 2015.

4. Kwon T, Rho JK, Lee JC, Park YH, Shin HJ, Cho S, Kang YK, Kim BY, Yoon DY and Yu DY: An important role for peroxiredoxin II in survival of A549 lung cancer cells resistant to gefitinib. Exp Mol Med 47: e165, 2015.

5. Yun CH, Mengwasser KE, Toms AV, Woo MS, Greulich H, Wong KK, Meyerson M and Eck MJ: The T790M mutation in EGFR kinase causes drug resistance by increasing the affinity for ATP. Proc Natl Acad Sci USA 105: 2070-2075, 2008.

6. Engelman JA and Jänne PA: Mechanisms of acquired resistance to epidermal growth factor receptor tyrosine kinase inhibitors in non-small cell lung cancer. Clin Cancer Res 14: 2895-2899, 2008.

7. Kwak EL, Sordella R, Bell DW, Godin-Heymann N, Okimoto RA, Brannigan BW, Harris PL, Driscoll DR, Fidias P, Lynch TJ, et al: Irreversible inhibitors of the EGF receptor may circumvent acquired resistance to gefitinib. Proc Natl Acad Sci USA 102: 7665-7670, 2005.

8. Kim Y, Ko J, Cui Z, Abolhoda A, Ahn JS, Ou SH, Ahn MJ and Park K: The EGFR T790M mutation in acquired resistance to an irreversible second-generation EGFR inhibitor. Mol Cancer Ther 11: 784-791, 2012

9. Finlay MR, Anderton M, Ashton S, Ballard P, Bethel PA, Box MR, Bradbury RH, Brown SJ, Butterworth S, Campbell A, et al: Discovery of a potent and selective EGFR inhibitor (AZD9291) of both sensitizing and T790M resistance mutations that spares the wild type form of the receptor. J Med Chem 57: 8249-8267, 2014.

10. Perrotti D and Neviani P: Protein phosphatase 2A: A target for anticancer therapy. Lancet Oncol 14: e229-e238, 2013.

11. Seshacharyulu P, Pandey P, Datta K and Batra SK: Phosphatase: PP2A structural importance, regulation and its aberrant expression in cancer. Cancer Lett 335: 9-18, 2013.

12. Schönthal AH: Role of serine/threonine protein phosphatase $2 \mathrm{~A}$ in cancer. Cancer Lett 170: 1-13, 2001.

13. Lv P, Wang Y, Ma J, Wang Z, Li JL, Hong CS, Zhuang Z and Zeng YX: Inhibition of protein phosphatase $2 \mathrm{~A}$ with a small molecule LB100 radiosensitizes nasopharyngeal carcinoma xenografts by inducing mitotic catastrophe and blocking DNA damage repair. Oncotarget 5: 7512-7524, 2014.

14. Junttila MR, Puustinen P, Niemelä M, Ahola R, Arnold H, Böttzauw T, Ala-aho R, Nielsen C, Ivaska J, Taya Y, et al: CIP2A inhibits PP2A in human malignancies. Cell 130: 51-62, 2007. 
15. Lucas CM, Harris RJ, Giannoudis A, Copland M, Slupsky JR and Clark RE: Cancerous inhibitor of PP2A (CIP2A) at diagnosis of chronic myeloid leukemia is a critical determinant of disease progression. Blood 117: 6660-6668, 2011.

16. Wang J, Li W, Li L, Yu X, Jia J and Chen C: CIP2A is overexpressed in acute myeloid leukaemia and associated with HL60 cells proliferation and differentiation. Int $\mathrm{J}$ Lab Hematol 33: 290-298, 2011.

17. Li W, Ge Z, Liu C, Liu Z, Björkholm M, Jia J and Xu D: CIP2A is overexpressed in gastric cancer and its depletion leads to impaired clonogenicity, senescence, or differentiation of tumor cells. Clin Cancer Res 14: 3722-3728, 2008.

18. Tseng LM, Liu CY, Chang KC, Chu PY, Shiau CW and Chen KF: CIP2A is a target of bortezomib in human triple negative breast cancer cells. Breast Cancer Res 14: R68, 2012.

19. Böckelman C, Hagström J, Mäkinen LK, Keski-Säntti H, Häyry V, Lundin J, Atula T, Ristimäki A and Haglund C: High CIP2A immunoreactivity is an independent prognostic indicator in early-stage tongue cancer. Br J Cancer 104: 1890-1895, 2011.

20. Böckelman C, Lassus H, Hemmes A, Leminen A, Westermarck J Haglund C, Bützow R and Ristimäki A: Prognostic role of CIP2A expression in serous ovarian cancer. Br J Cancer 105: 989-995, 2011.

21. Liu Z, Ma L, Wen ZS, Hu Z, Wu FQ, Li W, Liu J and Zhou GB Cancerous inhibitor of PP2A is targeted by natural compound celastrol for degradation in non-small-cell lung cancer. Carcinogenesis 35: 905-914, 2014.

22. Ma L, Wen ZS, Liu Z, Hu Z, Ma J, Chen XQ, Liu YQ, Pu JX, Xiao WL, Sun HD, et al: Overexpression and small moleculetriggered downregulation of CIP2A in lung cancer. PLoS One 6: e20159, 2011.

23. Zhou GB, Kang H, Wang L, Gao L, Liu P, Xie J, Zhang FX, Weng XQ, Shen ZX, Chen J, et al: Oridonin, a diterpenoid extracted from medicinal herbs, targets AML1-ETO fusion protein and shows potent antitumor activity with low adverse effects on $\mathrm{t}(8 ; 21)$ leukemia in vitro and in vivo. Blood 109 : 3441-3450, 2007.

24. Li Y, Wang Y, Wang S, Gao Y, Zhang X and Lu C: Oridonin phosphate-induced autophagy effectively enhances cell apoptosis of human breast cancer cells. Med Oncol 32: 365, 2015

25. Zhao Z and Chen Y: Oridonin, a promising antitumor natural product in the chemotherapy of hematological malignancies. Curr Pharm Biotechnol 15: 1083-1092, 2014.

26. Wang YY, Lv YF, Lu L and Cai L: Oridonin inhibits mTOR signaling and the growth of lung cancer tumors. Anticancer Drugs 25: 1192-1200, 2014.

27. Xu B, Shen W, Liu X, Zhang T, Ren J, Fan Y and Xu J: Oridonin inhibits BxPC-3 cell growth through cell apoptosis. Acta Biochim Biophys Sin (Shanghai) 47: 164-173, 2015.

28. Liu Y, Cao W, Zhang B, Liu YQ, Wang ZY, Wu YP, Yu XJ, Zhang XD, Ming PH, Zhou GB, et al: The natural compound magnolol inhibits invasion and exhibits potential in human breast cancer therapy. Sci Rep 3: 3098, 2013.

29. Cao W, Liu Y, Zhang R, Zhang B, Wang T, Zhu X, Mei L, Chen H, Zhang H, Ming P, et al: Homoharringtonine induces apoptosis and inhibits STAT3 via IL-6/JAK1/STAT3 signal pathway in Gefitinib-resistant lung cancer cells. Sci Rep 5: 8477, 2015.

30. Liu H, Gu Y, Wang H, Yin J, Zheng G, Zhang Z, Lu M, Wang C and He Z: Overexpression of PP2A inhibitor SET oncoprotein is associated with tumor progression and poor prognosis in human non-small cell lung cancer. Oncotarget 6: 14913-14925, 2015.
31. Gao J, Liu X, Yang F, Liu T, Yan Q and Yang X: By inhibiting Ras/ Raf/ERK and MMP-9, knockdown of EpCAM inhibits breast cancer cell growth and metastasis. Oncotarget 6: 27187-27198, 2015.

32. Yang XS, Liu SA, Liu JW and Yan Q: Fucosyltransferase IV enhances expression of MMP-12 stimulated by EGF via the ERK1/2, p38 and NF- $\mathrm{B}$ p pathways in A431 cells. Asian Pacific journal of cancer prevention. Asian Pac J Cancer Prev 13: $1657-1662,2012$

33. Hofmann HS, Hansen G, Richter G, Taege C, Simm A, Silber RE and Burdach S: Matrix metalloproteinase-12 expression correlates with local recurrence and metastatic disease in non-small cell lung cancer patients. Clin Cancer Res 11: 1086-1092, 2005.

34. Radisavljevic Z: AKT as locus of cancer multidrug resistance and fragility. J Cell Physiol 228: 671-674, 2013.

35. Hu HZ, Yang YB, Xu XD, Shen HW, Shu YM, Ren Z, Li XM, Shen HM and Zeng HT: Oridonin induces apoptosis via PI3K/Akt pathway in cervical carcinoma HeLa cell line. Acta Pharmacol Sin 28: 1819-1826, 2007.

36. Brodie SA, Li G, Harvey D, Khuri FR, Vertino PM and Brandes JC: Small molecule inhibition of the CHFR-PARP1 interaction as novel approach to overcome intrinsic taxane resistance in cancer. Oncotarget 6: 30773-30786, 2015.

37. Liu Y, Liu JH, Chai K, Tashiro S, Onodera S and Ikejima T: Inhibition of c-Met promoted apoptosis, autophagy and loss of the mitochondrial transmembrane potential in oridonininduced A549 lung cancer cells. J Pharm Pharmacol 65: 1622-1642, 2013.

38. Pritchard VL, Dimond L, Harrison JS, S Velázquez CC, Zieba JT, Burton RS and Edmands S: Interpopulation hybridization results in widespread viability selection across the genome in Tigriopus californicus. BMC Genet 12: 54, 2011.

39. Wang S, Yu S, Shi W, Ge L, Yu X, Fan J and Zhang J: Curcumin inhibits the migration and invasion of mouse hepatoma Hca-F cells through down-regulating caveolin-1 expression and epidermal growth factor receptor signaling. IUBMB Life 63: 775-782, 2011.

40. Hsieh CY, Tsai PC, Tseng CH, Chen YL, Chang LS and Lin SR: Inhibition of EGF/EGFR activation with naphtho[1,2-b]furan4,5-dione blocks migration and invasion of MDA-MB-231 cells. Toxicol In Vitro 27: 1-10, 2013.

41. Hu Y, Chen F, Liu F, Liu X, Huang N, Cai X, Sun Y, Li A and Luo R: Overexpression of TIP30 inhibits the growth and invasion of glioma cells. Mol Med Rep 13: 605-612, 2016.

42. Tsai JR, Liu PL, Chen YH, Chou SH, Cheng YJ, Hwang JJ and Chong IW: Curcumin Inhibits non-small cell lung cancer cells metastasis through the adiponectin/NF- $\kappa \mathrm{B} / \mathrm{MMPs}$ signaling pathway. PLoS One 10: e0144462, 2015.

43. Hwang J, Kim Y, Kang HB, Jaroszewski L, Deacon AM, Lee H, Choi WC, Kim KJ, Kim CH, Kang BS, et al: Crystal structure of the human $\mathrm{N}$-Myc downstream-regulated gene 2 protein provides insight into its role as a tumor suppressor. J Biol Chem 286: 12450-12460, 2011.

44. Cai J, Li R, Xu X, Zhang L, Wu S, Yang T, Fang L, Wu J, Zhu X, Li M, et al: URGCP promotes non-small cell lung cancer invasiveness by activating the NF- $\kappa$ B-MMP-9 pathway. Oncotarget 6: 36489-36504, 2015.

45. Sen T and Chatterjee A: Epigallocatechin-3-gallate (EGCG) downregulates EGF-induced MMP-9 in breast cancer cells: Involvement of integrin receptor $\alpha 5 \beta 1$ in the process. Eur J Nutr 50: 465-478, 2011. 